\title{
APLICAÇÃO DO INDÍCE DE TRANSFORMAÇÃO ANTRÓPICA NA ANÁLISE MULTITEMPORAL DA BACIA DO CÓRREGO DO BEZERRO VERMELHO EM TANGARÁ DA SERRA-MT ${ }^{1}$
}

\author{
Rogerio Gonçalves Lacerda de Gouveia², Edinéia Aparecida dos Santos Galvanin³ e Sandra Mara Alves
} da Silva Neves ${ }^{4}$

\begin{abstract}
RESUMO - Os objetivos deste trabalho foram identificar e quantificar o uso da terra na Bacia Hidrográfica do Córrego do Bezerro Vermelho no Município de Tangará da Serra, MT, por meio das imagens Landsat TM dos anos 1984 e 2011. As imagens foram georreferenciadas, classificadas e processadas no software Spring e as classes temáticas, quantificadas e editadas no software Arcgis. O grau de antropização foi verificado através do Índice de Transformação Antrópica. Foram identificadas cinco classes, cobertura florestal, vegetação secundária, agricultura, pastagem e lâmina de água. Os resultados indicaram diminuição nos percentuais das classes: de 35,35\% na cobertura florestal, de 11,78\% em pastagens e de 100\% na vegetação secundária, decréscimos esses relacionados ao aumento de $248,75 \%$ da agricultura. Portanto, este trabalho evidenciou alteração drástica da paisagem e, por meio do Índice de Transformação Antrópica, verificou-se aumento de 4,75 para 5,88 entre os anos 1984 e 2011, ou seja, a área de estudo encontrava-se na classe regular e passou a ser degradada, fato esse decorrente, sobretudo, das atividades antrópicas, associadas à expansão da agricultura.
\end{abstract}

Palavras-chave: Desmatamento; Conservação ambiental; Geotecnologias.

\section{APPLICATION OF ANTHROPIC TRANSFORMATION INDEX FOR MULTITEMPORAL ANALYSIS OF THE CÓRREGO DO BEZERRO VERMELHO BASIN TANGARÁ DA SERRA-MT}

\begin{abstract}
This paper describes the identification and quantification of land use changes in the Córrego do Bezerro Vermelho basin, Tangará da Serra, MT, using Landsat images from 1984 and 2011. Images were geo-referenced, classified, and processed by Spring software, and thematic classes were edited and quantified using ArcGis software. The Anthropic Transformation Index was applied to determine the degree of anthropization of the creek. Five classes were identified: forest cover, secondary vegetation, agriculture, pasture, and water bodies. The results indicated a decrease in the class percentiles: $35.35 \%$ of forest cover; 11,78\% of pastures; and $100 \%$ of secondary vegetation, all related to a $248.75 \%$ increase in agriculture. The findings of this study indicated that the landscape was drastically altered due to an increase in the Anthropic Transformation Index from 4,75 to 5.88 between 1984 and 2011. Thus, the creek, which that was classified as a regular class in 1984, passed to a degraded class in 2011, due to anthropogenic activities associated with agricultural expansion.
\end{abstract}

Keywords: Deforestation; Environmental conservation; Geotechnology.

\footnotetext{
${ }^{1}$ Recebido em 24.03.2013 aceito para publicação em 23.10.2013.

${ }^{2}$ Programa de Pós-graduação em Ambiente e Sistemas de Produção Agrícola, Universidade do Estado de Mato Grosso, UNEMAT, Brasil. E-mail:<rglgouveia@gmail.com>.

${ }^{3}$ Universidade do Estado de Mato Grosso, UNEMAT, Brasil. E-mail:<galvanin@gmail.com>.

${ }^{4}$ Departamento de Geografia - UNEMAT- Cáceres - MT. E-mail:<ssneves@unemat.br >.
} 


\section{INTRODUÇÃO}

A ausência de planejamento no uso da terra de uma região, objetivando máximos lucros com mínimos custos, sem a preocupação com o ambiente, pode acarretar consequências negativas à sociedade. O planejamento da ocupação da bacia hidrográfica torna-se necessário para racionalmente compatibilizar necessidades crescentes das atividades antrópicas com recursos limitados (TUCCI, 2002; ZACCHI et al., 2012). Ocrescimento de empresas madeireiras e mineradoras, aumento da malha viária, migração populacional, incêndios realizados no manejo de pastagem e cultivos agrícolas são atividades antrópicas que contribuem, de maneira significativa, para o desmatamento (LAURENCE et al., 2001).

O aumento do desmatamento no Brasil é notório, e diversos autores como Margulis (2003) e Chioveto et al. (2012) evidenciaram a preocupação com o crescente aumento do desmatamento na Amazônia brasileira. No bioma Pantanal, conforme Silva et al. (2010), houve aumento na perda de área natural de $15 \%$ até o ano 2008. A dinâmica do desmatamento ocorre pela expansão de propriedades que buscam aumentar a sua área destinada à pecuária extensiva aliada à extração de madeira ilegal, a qual é seguida pelo cultivo da soja (BERMANN, 2008).

De acordo com Silva et al. (2011), observa-se a degradação do ambiente no rio Paraguai, o qual é o principal rio formador do bioma Pantanal. As consequências do desmatamento, segundo Souza et al. (2011), são a erosão, a perda da biodiversidade e o comprometimento de nascentes.

O desmatamento pode ser investigado e monitorado por meio de imagens de satélite, o que, por sua vez, possibilita a análise visual, delineamento de características de interesse através do reconhecimento assistido por computador dos padrões espectrais destinados à análise estatística, incluindo a criação de uma base de dados quantitativos (KIRCHNER, 1983).

Nesse contexto, as geotecnologias que se utilizam de técnicas matemáticas e computacionais para o tratamento de informação geográfica composta por cartografia digital, sensoriamento remoto, SIG e georreferenciamento (CÂMARA et al., 1998) surgem como importantes ferramentas de monitoramento do desmatamento e do uso da terra (NASCIMENTO et at., 2005). O Índice de Transformação Antrópica - ITA
(MATEO, 1991), que possibilita mensurar a pressão antrópica sobre algum componente da paisagem, mostra-se eficiente, pois, além de quantificar esse método, permite avaliar o grau de antropização específico que ocorre em cada unidade ambiental da paisagem analisada.

Nesse sentido, este trabalho objetivou quantificar a mudança no uso da terra na Bacia Hidrográfica do Córrego do Bezerro Vermelho (BHCBV), no Município de Tangará da Serra, MT, ocorrida no período de 1984 e 2011. Para tanto, foi avaliado o grau de antropização por meio do ITA. Este estudo se justificou pela importância que a bacia analisada tem para o referido munícipio, seja pela captação de água para o abastecimento da população urbana, seja pelo fato de integrar o sistema da Bacia do Rio Sepotuba, a qual está inserida na Bacia do Alto Paraguai (BAP), que se constitui em elemento estratégico para a gestão dos recursos hídricos no Brasil, na Bolívia e no Paraguai, por incluir o Pantanal Mato-Grossense, uma das maiores extensões de áreas alagadas do planeta.

\section{MATERIAL E MÉTODOS}

\section{1. Área do estudo}

A BHCBV está localizada na Região Centro-Oeste do Brasil, no médio Norte do Estado de Mato Grosso (Figura 1), apresentando uma área de 10.069,65 ha, situada entre as latitudes de $14^{\circ} 33^{\prime}$ ' $9,93^{\prime \prime} \mathrm{S}$ a $14^{\circ} 40^{\prime}$ $15,04^{\prime \prime S}$ e longitudes de $57^{\circ} 26^{\prime} 17,54^{\prime \prime} \mathrm{W}$ a $57^{\circ} 19^{\prime}$ 16, 02"W, contida nos limites do Município de Tangará da Serra, MT.

A fitoecologia da bacia consiste de Floresta Estacional Semidecidual (IBGE, 2004), sendo o relevo pertencente ao Planalto dos Parecis (IBGE, 2006), que possui $2 \%$ de relevo montanhoso, $3 \%$ de relevo ondulado e 95\% de relevo plano (BHRS, 2002). Os solos são formados por Latossolo Vermelho distroférrico, Podzólico VermelhoAmarelo eutrófico e Nitossolo Vermelho distrófico (IBGE, 2001). O clima é tropical semiúmido com quatro a cinco meses secos e temperatura média mensal acima de $18^{\circ} \mathrm{C}$, durante todo o ano (IBGE, 2002).

\subsection{Material}

Neste trabalho, foram utilizadas as imagens obtidas pelo sensor Thematic Mapper (TM) a bordo do satélite Landsat-5, com resolução espacial de 30 m, com órbitaponto 227/70, bandas do infravermelho médio, infravermelho próximo e vermelho, de 1984 e 2011. As

Revista Árvore, Viçosa-MG, v.37, n.6, p.1045-1054, 2013

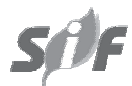




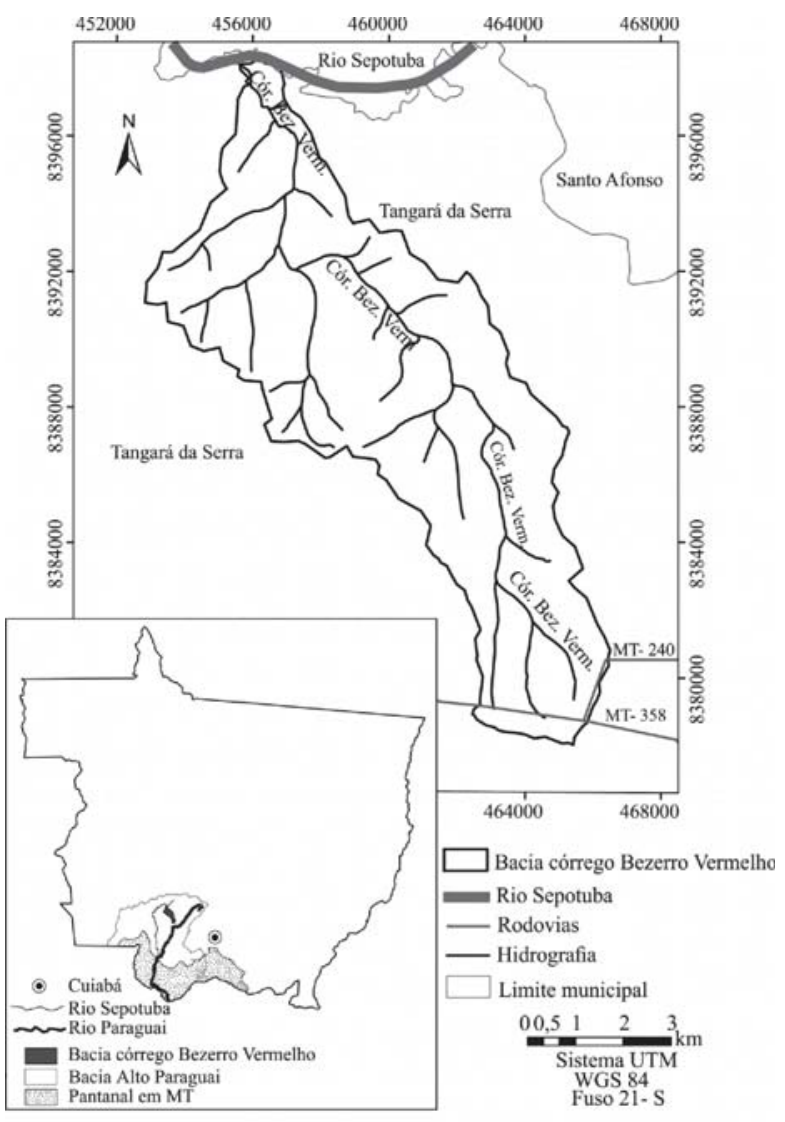

Figura 1 - Localização da Bacia do Córrego do Bezerro Vermelho no Município de Tangará da Serra e, no quadro, detalhe dessa bacia no Estado de Mato Grosso.

Figure 1 - Location of Córrego do Bezerro Vermelho in Tangará da Serra, and in detail, Mato Grosso State, Brazil.

imagens fazem parte do banco de imagens do Instituto Nacional de Pesquisas Espaciais (INPE), disponível na Web.

Utilizou-se o mapa vetorial do limite da BHCBV, disponibilizado pelo banco de dados de geoprocessamento IBGE/DSG da Secretaria de Estado do Meio Ambiente de Mato Grosso (http://www.sema.mt.gov.br).

O tratamento dos dados matriciais e vetoriais foram realizados nos softwares Arcgis, versão 9.2, da Esri e no Spring, versão 5.1, do INPE.

\subsection{Procedimentos metodológicos}

As imagens foram adquiridas no mesmo período sazonal do ano (período seco), nas datas de 8 de agosto de 1984 e 16 de junho de 2011, possibilitando, assim, interpretação mais confiável. Cabe ressaltar que, nesse período, ocorre menor presença de nuvens sobre as cenas.

A composição das imagens foi realizada no software Arcgis 9.2, utilizando-se as bandas 5, 4 e 3 na composição RGB. O georreferenciamento da imagem foi feito no software Arcgis, por meio dos pontos de controle coletados em campo, via Sistema de Posicionamento Global (GPS).

Realizou-se, nas imagens de 1984 e 2011, a classificação supervisionada com o classificador Maxver, no software Spring, considerando as classes pastagem, agricultura, cobertura florestal (Floresta Estacional Semidecidual), vegetação secundária (regeneração natural da cobertura florestal) e lâmina de água. Tanto a definição da classe de uso da terra quanto a seleção das áreas de treinamento para a classificação da imagem do ano 2011 tiveram confirmação a partir de resultado da visita a campo realizada no mês de julho de 2011. A validação da imagem de 1984 deu-se a partir dos mapas gerados no âmbito do Projeto Radambrasil (BRASIL, 1982b).

O ITA foi desenvolvido por Lémechev e aplicado por Mateo (1984), Vicens (1997) e Teixeira (2003), em estudos geoecológicos, cujo objetivo é quantificar a pressão antrópica sobre algum componente do meio ambiente, como áreas de proteção ambiental, bacias hidrográficas ou parques nacionais (ROCHA; CRUZ, 2009). O ITA é calculado a partir das classes do mapa de uso e cobertura da terra.

$$
I T A=\sum(\% U S O \times P E S O) / 100
$$

em que:

uso = área em valores percentuais da classe de uso e cobertura; e

peso $=$ peso dado aos diferentes tipos de uso e cobertura quanto ao grau de alteração antrópica - Varia de 1 a 10 , em que 10 indica as maiores pressões.

Cruz et al. (1998) classificaram o ITA em: pouco degradada (0 - 2,5), regular (2,5 - 5), degradada (5 $7,5)$ e muito degradada (7,5 - 10). A Tabela 1 apresenta os pesos do ITA de acordo com as classes de uso da terra encontrados. Por meio do método Delphi, foi atribuído o peso de acordo com a classe de uso, a partir da visão multidisciplinar de vários especialistas (NOGUEIRA et al., 2001).

Revista Árvore, Viçosa-MG, v.37, n.6, p.1045-1054, 2013 
Tabela 1 - Pesos atribuídos às classes de vegetação e uso da terra.

Table 1 - Weights assigned to classes of vegetation and land use.

\begin{tabular}{lc}
\hline Classes & Pesos \\
\hline Agricultura & 7,7 \\
Cobertura florestal & 1,0 \\
Lâmina d' água & 1,0 \\
Pastagem & 5,5 \\
Vegetação secundária & 3,0 \\
\hline
\end{tabular}

\section{RESULTADOS}

A partir do processamento digital de imagem do satélite Landsat, obtiveram-se os mapas de uso da terra para cinco classes principais nos anos em estudo, 1984 e 2011 (Figuras 2 e 3). Houve dificuldades em diferenciar as classes pastagem, vegetação secundária e cobertura florestal, devido à similaridade de coloração do pixel. Para melhorar a acurácia, realizou-se visita a campo, de modo a convalidar as feições discriminadas.

Na Tabela 2 são mostradas as informações quantitativas de distribuição das classes de ocupação da terra e do índice de transformação antrópica na BHCBV, entre os anos 1984 e 2011.

Na Figura 2a, relativa a 1984, a classe predominante de uso da terra é a pastagem. Essa classe ocupava 52,66\% e era encontrada em maior quantidade na porção Norte e Central, com menor presença na porção Sul, totalizando uma área de 5.302,69 ha. Em 2011 (Figura 2b), a pastagem continuou a ocupar a maior área (Tabela 2), substituída em parte pela agricultura, que obteve aumento de 2.518,38 ha.

Com a expansão da agricultura por toda a área da bacia no ano 2011, esta passou a ocupar $41,82 \%$ da área total (Tabela 2).

A cobertura florestal diminuiu no período de 1984 a 2011, ou seja, houve desmatamento da vegetação nativa, sendo a área desmatada ocupada pela agricultura (Tabela 2).

A vegetação secundária, que consiste na regeneração natural da cobertura florestal, demonstrou redução total da área ocupada por essa classe no período analisado (Tabela 2), cedendo para a agricultura a ocupação dessas áreas.
Em 1984, a presença da classe lâmina de água, que compreende os açudes e represas, foi 20 ha. No ano 2011, ocorreu a presença da classe lâmina de água, sendo essa a classe de menor expressão de uso da terra.

A partir da Figura 3a, que retrata o ITA no ano 1984, pode-se observar que ocorreu maior degradação na porção Sul, embora as áreas degradadas estivessem distribuídas por toda a bacia. As áreas classificadas como regulares (Tabela 1) encontraramse distribuídas por toda a bacia, porém de forma fragmentada, e as áreas classificadas como pouco degradadas estão situadas, principalmente, ao longo dos cursos dos rios.

Na Figura 3b, que mostra o ITA em 2011, pode-se observar que as áreas classificadas como muito degradadas (Tabela 1) continuam localizadas na porção Sul com a expansão em direção ao Centro-Norte, enquanto as áreas pouco degradadas diminuíram no Sul, mas estiveram presentes em toda a bacia. As áreas pouco degradadas restringiram-se aos cursos d’água, e as áreas regulares, no caso a vegetação secundária, foram totalmente suprimidas devido à expansão da classe muito degradada.

\section{DISCUSSÃO}

A diminuição das classes de uso da terra devido à expansão da agricultura, deve-se ao fato de essa atividade ser uma exploração mais rentável ao produtor. Esse resultado está de acordo com o exposto no trabalho realizado por Ortiz et al. (2005) e Passos et al. (2010), que confirmaram o avanço da agricultura em áreas onde predominavam a vegetação nativa, devido às características edafoclimáticas e geoeconômicas favoráveis da região.

O Estado de Mato Grosso é considerado o maior produtor de grãos do Brasil, com destaque para a soja, além da produção de fibras de algodão e cana-de-açúcar. Como consequência, foi o estado que mais desmatou em áreas da floresta amazônica no ano 2007. Essa degradação ambiental tem despertado interesse por parte da sociedade na preservação do meio ambiente (CASARIN et al., 2008). A expansão da agricultura no Brasil vem se consolidando com elevado potencial degradante ao meio ambiente, o que dificulta a venda de produtos no mercado internacional, cada vez mais exigente com as questões ambientais globais, fazendo-

Revista Árvore, Viçosa-MG, v.37, n.6, p.1045-1054, 2013 
se necessárias políticas ambientais que definem um padrão de sustentabilidade sem comprometer a competitividade (FEIX et al., 2010).

Valle Junior et al. (2012) realizaram um diagnóstico da mudança do uso da terra entre 1978 e 2011 na área do Instituto Federal de Tecnologia do Triângulo Mineiro.
Esse estudo mostrou que a vegetação nativa reduziu em 19,19\% sua área ocupada, sendo substituída pela agricultura e pastagem.

Rodrigues e Hott (2010) estudaram a dinâmica da vegetação natural no Nordeste do Estado de São Paulo, entre 1988 e 2003. Verificaram que a área de remanescentes

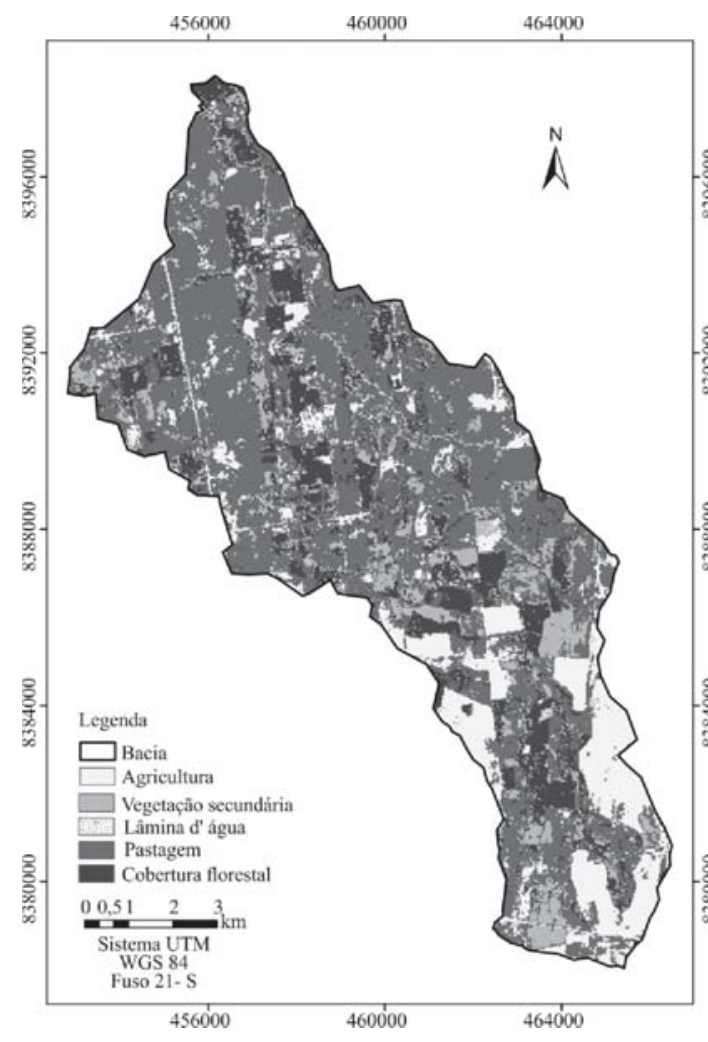

(a)

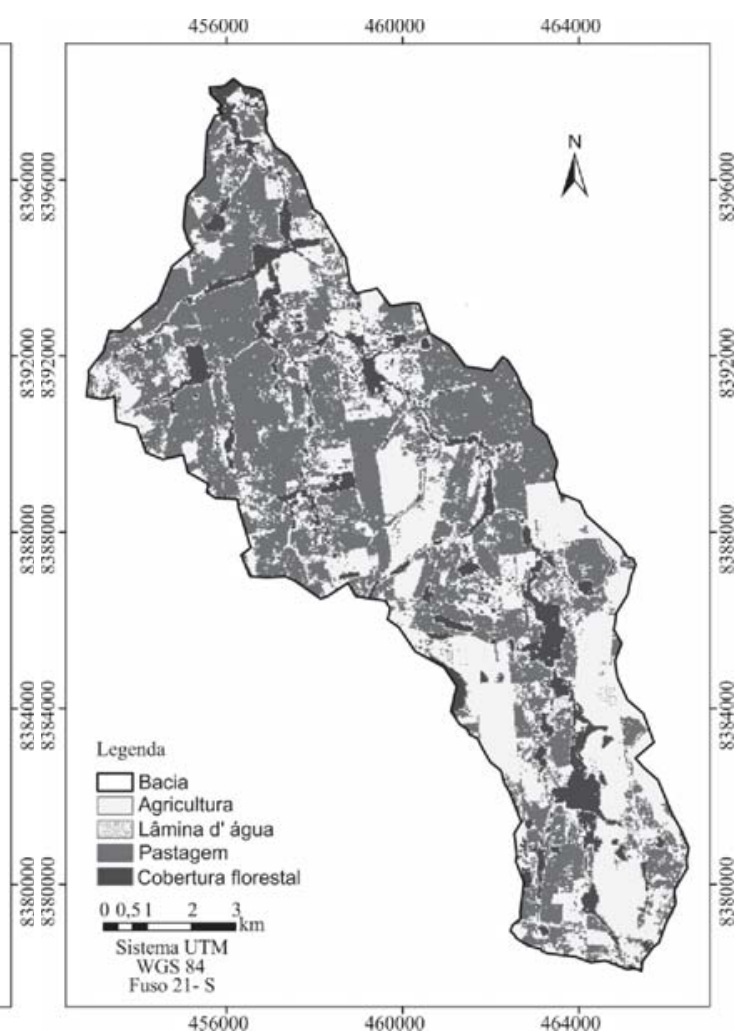

(b)

Figura 2 - Distribuição das classes temáticas da área de estudo: (a) ano 1984 e (b) ano 2011.

Figure 2 - Distribution of thematic classes of the study area: (a) 1984 and (b) 2011.

Tabela 2 - Distribuição das classes de ocupação da terra na Bacia do Córrego do Bezerro Vermelho. Table 2 -Distribution of classes of land occupation in the basin of the Córrego do Bezerro Vermelho.

\begin{tabular}{lcccccccc}
\hline \multirow{2}{*}{ Classes } & \multicolumn{2}{c}{ Área total da classe } & \multicolumn{2}{c}{} & & & \\
& \multicolumn{2}{c}{ Em ha } & Em \% & & Mudançaem \% & \multicolumn{2}{c}{ ITA } \\
& 1984 & 2011 & 1984 & 2011 & & 1984 & 2011 \\
\hline Agricultura & $1.692,99$ & $4.211,37$ & 16,82 & 41,82 & 248,75 & 1,2951 & 3,2201 \\
Pastagem & $5.302,69$ & $4.677,66$ & 52,66 & 46,45 & $-11,78$ & 2,8963 & 2,5548 \\
Cobertura florestal & $1.777,68$ & $1.149,12$ & 17,65 & 11,41 & $-35,35$ & 0,1765 & 0,1141 \\
Vegetação secundária & $1.276,29$ & 0 & 12,67 & 0 & -100 & 0,3801 & 0,0000 \\
Lâmina d'água & 20,00 & 31,50 & 0,20 & 0,32 & 36,50 & $-0,002$ & 0,0032 \\
TOTAL & $10.069,65$ & $10.069,65$ & 100 & 100 & - & 4,7500 & 5,8800 \\
\hline
\end{tabular}




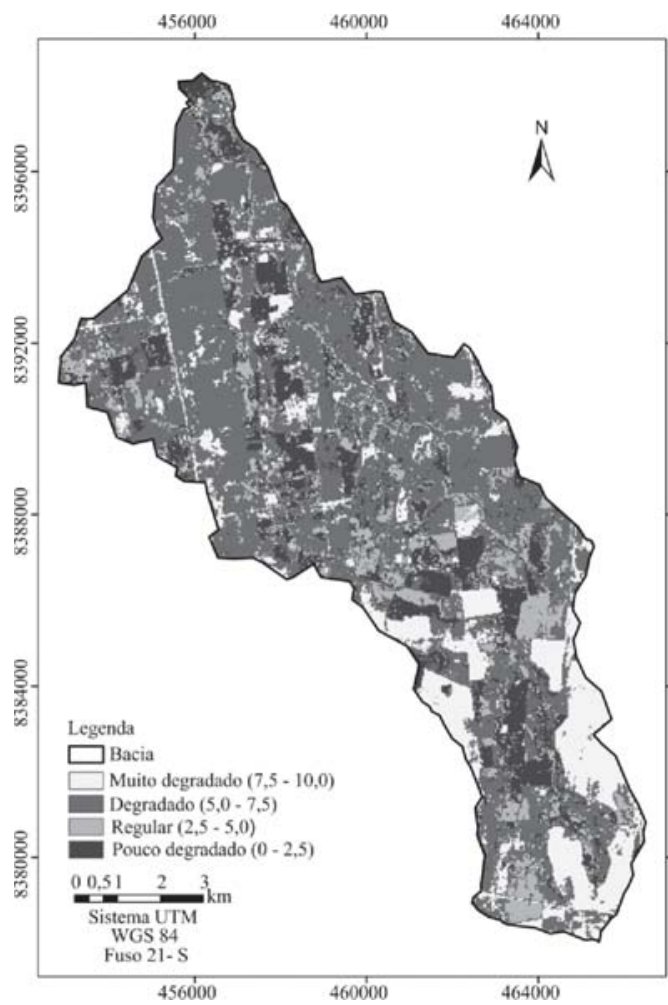

(a)

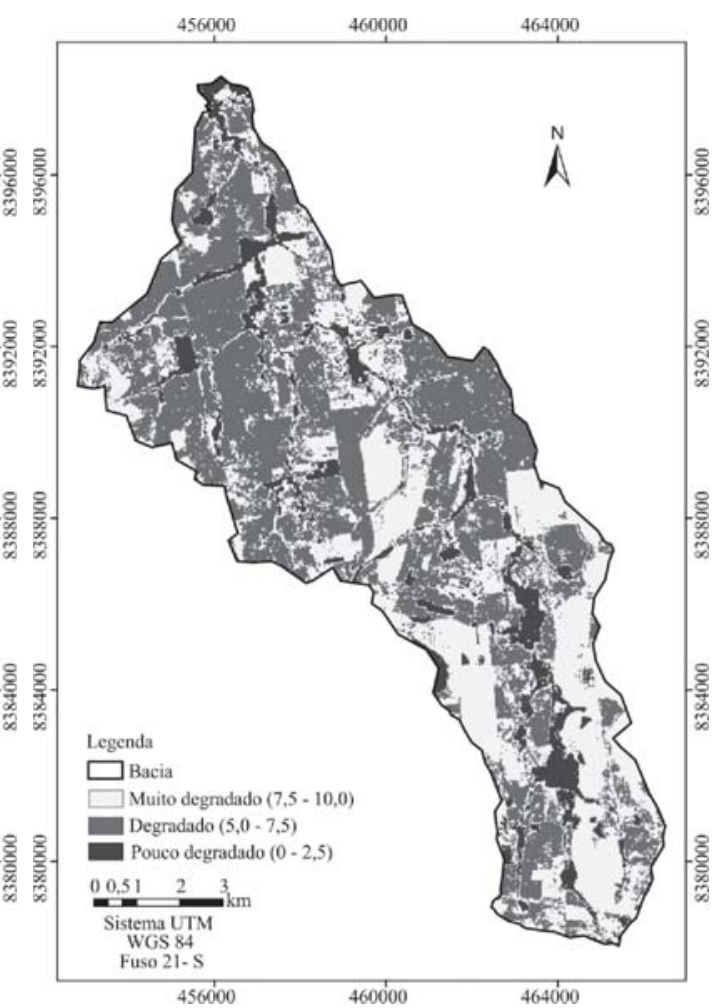

(b)

Figura 3 - Distribuição do índice de transformação antrópica: (a) ano 1984 e (b) ano 2011.

Figure 3 - Distribution of anthropic transformation index: (a) 1984 and (b) 2011.

de vegetação natural sofreu retração, sendo substituída por outros usos e coberturas das terras, como a cultura da cana-de-açúcar ocupando 176,5 km², as pastagens que avançaram por $99,9 \mathrm{~km}^{2}$, a silvicultura que ocupa $67,9 \mathrm{~km}^{2}$ e outras culturas, como as anuais e irrigadas.

Apesar da diminuição da área de ocupação da terra na área nos últimos anos, a pastagem continua a predominar na maior parte. Esse dado está de acordo com Alves Filho et al. (2012), que diagnosticaram um remanescente florestal na área de influência de uma usina de cana-de-açúcar na região do Triângulo Mineiro, constatando que a pastagem ocupava 73,80\% da área total de 208.200 ha, fragmentando os $10,07 \%$ de remanescentes florestais, onde o gado tinha livre acesso, comprometendo a qualidade ambiental desses fragmentos.

A vegetação secundária que estava presente em 1984 foi eliminada no ano 2011 (Tabela 2). Estudos sobre a vegetação secundária na Amazônia legal brasileira demonstram que, à medida que a ocupação de uma região se consolida e o desmatamento e o uso da terra se intensificam, por meio da exploração agropecuária, e o abandono da terra e a consequente formação de vegetação secundária diminuem (ALMEIDA et al., 2010).

Áreas pouco degradadas estão concentradas próximas às Áreas de Preservação Permanente (APP) nas margens dos rios. Esse dado é confirmado por Vanzela et al. (2009) que, ao estudarem o córrego Três Barras, em Marinópolis, SP, observaram maior presença de atividade pouco degradante (florestas) no curso dos rios em áreas de APP em relação ao restante da bacia, onde predominam atividades classificadas como muito degradantes (Figura 3ab).

Em determinados trechos de APP, foram verificadas as classes degradado e muito degradado, de acordo com a imagem do ano 2011. Soares et al. (2011), realizando um mapeamento de APP na Bacia Hidrográfica do Ribeirão São Bartolomeu, MG, verificaram que 59,70\% da APP

Revista Árvore, Viçosa-MG, v.37, n.6, p.1045-1054, 2013 
era utilizada ilegalmente em atividades agropecuárias; a classe pastagem destaca-se, ocupando $40,06 \%$ e o cafezal, 7,12\%.

O Código Florestal define que as APPs são consideradas áreas protegidas cobertas ou não com vegetação nativa com a função de preservar os recursos hídricos, a paisagem e a biodiversidade. No caso de APP no curso de rios, a área a ser preservada é proporcional à sua largura (BRASIL, 2012).

O aumento significativo do uso da terra por meio da agricultura verificado vem ao encontro dos estudos realizados por Lazzarotto et al. (2009), que, comparando os sistemas de produção agrícola, verificaram que a agricultura é atividade mais rentável do que a pecuária, proporcionando o aumento da área plantada.

Ferreira et al. (2009) verificaram dependência entre a cobertura vegetal nativa e o preço da terra no Estado de Goiás. Percebeu-se, claramente, a desvalorização das terras em áreas cuja porção de remanescentes de Cerrado é maior. As áreas mais preservadas do Estado, em geral concentradas no Nordeste goiano, reúnem os municípios com as terras menos valorizadas, evidenciando aumento gradual da fronteira agrícola.

Entre as culturas classificadas como agricultura, encontram-se os grãos, a fruticultura e a cana-de-açúcar. A expansão da agricultura é citada nos trabalhos de Menke et al. (2009), afirmando que essa expansão é devida a condições ambientais favoráveis como terras planas e estação chuvosa bem definida. Klink et al. (2005) verificaram que o uso de tecnologias modernas, como o plantio de sementes geneticamente modificadas, reduz custos de produção e estimula a expansão.

A classe pastagem resultou na forma de uso da terra mais expressiva durante o período analisado. Segundo Margulis (2003), a pecuária é a atividade antrópica que predomina em extensas áreas em virtude do baixo investimento quando comparado com a agricultura, constituindo um dos principais agentes agressivos ao meio ambiente, quando ocupa áreas destinadas a APP (NASCIMENTO et al., 2005).

A redução significativa da cobertura florestal em fragmentos e APP de rios também é citada por Sarcinelli et al. (2012), que avaliaram a representatividade ambiental de áreas protegidas em áreas de plantios homogêneos de eucalipto, onde foram encontrados diferentes percentuais de área destinada à preservação ambiental.
As florestas nativas ocupavam pouco mais da metade, 51,9\% da área denominada Florália, os eucaliptais 76\% da área e restando $24 \%$ de fragmentos florestais nativos.

É importante destacar que a área de vegetação nativa é de apenas $11,41 \%$ do total da área, demonstrando que o estágio de degradação se encontra avançado, contrariando o que prevê a Lei 12.651/2012, art. 12, inciso $4^{\circ}$, que dispõe que a área a ser preservada com vegetação nativa em áreas de florestas é de 50\% (BRASIL, 2012).

A supressão total da vegetação secundária em 2011 evidencia o alto estágio de degradação atual. A importância da vegetação secundária na composição de matéria orgânica, que em baixos teores no solo resulta em degradação, foi demonstrado em trabalhos, em que se verificou que a vegetação secundária tem maior influência na composição da matéria orgânica do solo do que o eucalipto e as pastagens (COUTINHO et al., 2010).

O monitoramento da vegetação secundária é fundamental no acompanhamento dessa mudança de uso e ocupação da terra, já que denota o potencial que garante a transição florestal e indica reversão na tendência de desmatamento (FARINACI; BATISTELLA, 2012).

Cheung et al. (2009) concluíram que a presença de pastagem afeta negativamente a regeneração da mata, principalmente a gramínea Brachiaria decubens, devido à sua adaptação a solos com poucos nutrientes, rápido crescimento e maior acúmulo de biomassa vegetal.

A presença de lâmina de água na bacia mostra que os açudes e as represas são utilizados pelos agricultores para várias finalidades, entre elas se destacando a irrigação. Cabe ressaltar que essa atividade utiliza aproximadamente $70 \%$ da água disponível no Brasil, fundamental ao aumento de produtividade das culturas (HESPANHOL et al., 2002) e à atividade de piscicultura, que aumentou significativamente nos últimos anos devido ao grande potencial hídrico disponível proveniente das numerosas represas espalhadas pelo país (CAMARGO; POUEY, 2005).

\section{CONCLUSÕES}

Este trabalho demonstrou as mudanças ocorridas na paisagem da bacia de estudo ao longo de 27 anos, destacando-se, principalmente, a diminuição da cobertura florestal nativa da área total da bacia e a

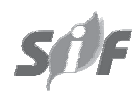

Revista Árvore, Viçosa-MG, v.37, n.6, p.1045-1054, 2013 
diminuição em $100 \%$ da área ocupada pela vegetação secundária. De modo geral, a bacia investigada encontra-se com 88,59\% da área ocupada por atividades antrópicas.

O ITA possibilitou qualificar os níveis de degradação ambiental de acordo com o uso da terra na área da bacia, ou seja, esta passou de regular no ano 1984 para degradada em 2011.

As ferramentas geotecnológicas, como o Sensoriamento Remoto e os Sistemas de Informação Geográfica, possibilitaram a geração, a quantificação das classes dos mapas e o monitoramento do uso da terra da Bacia do Córrego do Bezerro Vermelho.

\section{AGRADECIMENTOS}

À CAPES, pelo apoio em forma de bolsas de mestrado, sendo uma delas vinculada ao Projeto de Pesquisa "Modelagem de indicadores ambientais para a definição de áreas prioritárias e estratégicas à recuperação de áreas degradadas da região Sudoeste de Mato Grosso, MT”, vinculada à sub-rede de estudos sociais, ambientais e de tecnologias para o sistema produtivo na região Sudoeste mato-grossense - REDE ASA, financiada no âmbito do Edital MCT/CNPq/ FNDCT/FAPs/MEC/CAPES/PRO-CENTRO-OESTE $n^{\circ}$ 031/2010.

\section{REFERÊNCIAS}

ALMEIDA, C. A. et al. Estimativa de área de vegetação secundária na amazônia legal brasileira. Revista Acta Amazonica, v.40, n.2, p.289-302, 2010.

ALVES FILHO, A. A. et al. Diagnóstico de remanescente florestal nativo na área de influência direta da usina Santa Vitória, na região do Triângulo Mineiro- MG. Enciclopédia Biosfera, v.8, n.15, p.682-695, 2012.

BERMANN, C. Crise ambiental e as energias renováveis. Ciência e Cultura, v.60, n.3, p.20-29, 2008.

BACIA HIDROGRÁFICA DO RIO SEPOTUBA BHRS.. Projeto de recuperação socioeconômico- ambiental. Tangará da Serra- MT. Tangará da Serra - MT: Secretaria Municipal de Agricultura e Meio Ambiente, 2002.
BRASIL. Lei n. ${ }^{\circ}$ 12. 651, de 25 de maio de 2012. Dispõe sobre a proteção da vegetação nativa. Diário Oficial da União, Brasília, DF, 25 maio de 2012. Disponível em: < http:// www.planalto.gov.br/ccivil_03/_Ato2011-2014/2012/ Lei/L12651.htm>. Acesso em: 07 de ago. de 2012.

BRASIL. Ministério das Minas e Energia. Secretaria- Geral. Projeto RADAMBRASIL. Folha SD 21 Cuiabá; geologia, geomorfologia, pedologia, vegetação e uso potencial da terra. Rio de Janeiro: 1982. 520p.

CÂMARA, G.; MEDEIROS, J. S. Princípios básicos e geoprocessamento. In: Sistemas de Informações Geográficas. Aplicações na agricultura. 2.ed. Brasília: Embrapa/SPI/ Embrapa-CPAC, 1998. 434p.

CAMARGO, S. G. O.; POUEY, J. L. O. F. Aquicultura- Um mercado em expansão. Revista Brasileira de Agrociência, v.11, n.4, p.393396, 2005.

CASARIN, R. et al. Uso da terra e qualidade da água da bacia hidrográfica Paraguai/JauquaraMT. Revista Geográfica Acadêmica, v.2, n.1, p.33-42, 2008.

CHEUNG, K. C. et al. Relação entre a presença de vegetação herbácea e a regeneração natural de espécies lenhosas em pastagem abandonadas na floresta ombrófila densa do sul do Brasil. Acta BotanicaBrasilica, v.23, n.4, p.1048- 1056, 2009.

CHIOVETO, A. T. et al. Análise da dimensão do desflorestamento por meio do uso de imagens de satélite em um município da amazônia legal brasileira, Publicatio UEPG, v.20, n.1, p.1733, 2012.

COUTINHO, R. P. et al. Estoque de carbono e nitrogênio e emissão de $\mathrm{n}_{2} \mathrm{o}$ em diferentes usos do solo na Mata Atlântica. Pesquisa

Agropecuária Brasileira, v.45, n.2, p.195203, 2010.

ROCHA, S. P.; CRUZ, C. B. M. Aplicação do ITA na análise espaço-temporal do entorno da BR-101 nos municípios de Angra dos Reis e Parati. In: SIMPÓSIO BRASILEIRO DE SENSORIAMENTO REMOTO, 2009, Natal. Anais... Natal: 2009. p.1505-1512. 
CRUZ, C. B. M. et al. Carga antrópica da bacia hidrográfica da Baía de Guanabara. In: SIMPÓSIO BRASILEIRO DE SENSORIAMENTO REMOTO, 1998, Santos. Anais.... Santos: 1998. p.99-109.

FARINACI, J. S.; BATISTELLA, M. Variação na cobertura vegetal nativa em São Paulo: um panorama do conhecimento atual. Revista Árvore, v.36, n.4, p.695-705, 2012.

FEIX, R. D. et al. Comércio internacional , agricultura e meio ambiente: teorias, evidências e controvérsias empíricas. Revista de Economia e Sociologia Rural, v.48, n.3, p.605-634, 2010.

FERREIRA, M. E. et al. Ativos ambientais do bioma cerrado: uma análise da cobertura vegetal nativa e sua relação com o preço da terra no estado Goiás. Revista Brasileira de Cartografia, n.61/01, p.37-50, 2009.

HESPANHOL, I. Potencial de reuso de água no Brasil, agricultura, indústrias e municípios, recarga de aquíferos. Revista Brasileira de Recursos Hídricos, v.7, n.4, p.75-95, 2002.

\section{INSTITUTO BRASILEIRO DE GEOGRAFIA E} ESTATÍSTICA - IBGE. Mapa de biomas do Brasil: primeira aproximação. Rio de Janeiro: 2004. Disponível em: <ftp://geoftp.ibge.gov.br/ mapas_tematicos/mapas_murais/biomas.pdf $>$ Acesso em: 2 de jan. de 2013.

\section{INSTITUTO BRASILEIRO DE GEOGRAFIA E} ESTATÍSTICA - IBGE. Mapa de clima do Brasil: Rio de Janeiro: 2002. Disponível em: <ftp://geoftp.ibge.gov.br/mapas_tematicos/ mapas_murais/clima.pdf $>$ Acesso em: 13 de jan. de 2013.

\section{INSTITUTO BRASILEIRO DE GEOGRAFIA E} ESTATÍSTICA - IBGE. Mapa de solos do Brasil: Rio de Janeiro: 2001. Disponível em: <ftp:// geoftp.ibge.gov.br/mapas_tematicos/mapas_murais/ solos.pdf> Acesso em: 10 de jan. de 2013.

\section{INSTITUTO BRASILEIRO DE GEOGRAFIA E} ESTATÍSTICA - IBGE. Mapa de Unidades de Relevo do Brasil: segunda edição. Rio de Janeiro: 2006. Disponível em: <ftp:// geoftp.ibge.gov.br/mapas_tematicos/ mapas_murais/relevo_2006.pdf $>$ Acesso em: 5 de jan. de 2013.
KIRCHNER, F. F. Aplicação do sensoriamento remoto no planejamento regional. Revista Floresta, v.14, n.2, p.28-35, 1983.

KLINK, C. A.; MACHADO, R. B. A. conservação do cerrado brasileiro. Megadiversidade, v.1, n.1, p.147-155, 2005.

LAURENCE, W. F. et al. The future of the Baziliam Amazon. Science Magazine, v.291, n.5503, p.438-439, 2001.

LAZZAROTTO, J. J. et al. Volatilidade dos retornos econômicos associados à integração lavoura- pecuária no estado do Paraná. Revista de Economia e Agronegócio, v.7, n.2, p.259-283, 2009.

MARGULIS, S. Causas do desmatamento da Amazônia brasileira. Brasilia: Banco Mundial, 2003. 100p.

MAteo, J. Apuntes de Geografia de Los Paisajes. La Habana: Universitaria, 1984. 194p.

MENKE, A. B. et al. Análise das mudanças do uso agrícola da terra a partir de dados de sensoriamento remoto multitemporal do município Luís Eduardo Magalhaes - BA. Revista Sociedade e Natureza, v.21, n.3, p.315-329, 2009.

NASCIMENTO, M. C. et al. Uso do geoprocessamento na identificação de conflito de uso da terra em áreas de preservação permanente na bacia hidrográfica do rio Alegre, Espirito Santo. Ciência Florestal, v.15, n.2, p.207-220, 2005.

NOGUEIRA, C. R. et al. Classificação de bacias hidrográficas em tabuleiros costeiros através de indicadores provenientes de sensoriamento remoto - estudo de caso em Linhares e Sooretama, ES. In: SIMPÓSIO BRASILEIRO DE SENSORIAMENTO REMOTO, 2001, Foz do Iguaçu. Anais... Foz do Iguaçu: 2001.p.955-958.

Revista Árvore, Viçosa-MG, v.37, n.6, p.1045-1054, 2013 
ORTIZ, J. L.; FREITAS, M. I. C. Análise da transformação do uso da terra, vegetação e impactos ambientais por meio de sensoriamento remoto e geoprocessamento, Geociências, v.24, n.1, p.77-89, 2005.

PASSOS, A. L. O. et al. Evolução do uso do solo e agronegócio na região oeste do estado da Bahia. Cadernos de Geociência, n.7, p.31-39, 2010.

RODRIGUES, C. A. G.; HOTT, M. C. Dinâmica da vegetação natural no nordeste do estado de São Paulo, entre 1988 e 2003. Revista Árvore, v.34, n.5, p.881-887, 2010.

SARCINELLI, T. S. et al. Representatividade fisiográfica e pedológica de fragmentos de floresta nativa em áreas de plantios homogêneos de eucalipto. Revista Árvore, v.36, n.3, p.499-509, 2012.

SILVA, A. S. Mineração e áreas de preservação permanentes (APPs) em Santo Antônio de Pádua - RJ. Sociedade e Natureza, v.23, n.2, p.173-185, 2011.

SILVA, G. B. S. et al. Discriminação da cobertura vegetal do cerrado mato-grossense por meio da imagem MODIS. Pesquisa Agropecuária Brasileira, v.45, n.2, p.186-194, 2010.

SOARES, V. P. et al. Mapeamento de áreas de preservação permanentes e identificação dos conflitos legais de uso da terra na bacia hidrográfica do ribeirão São Bartolomeu - MG. Revista Árvore, v.35, n.3, p.555-563, 2011.

SOUZA, J. C. M. A educação ambiental na recuperação e conservação dos recursos naturais: a percepção de assentados rurais no cerrado goiano. Campo- Território, v.6, n.11, p.312-337, 2011.
TEIXEIRA, A. J. A. Classificação de bacias de drenagem com o suporte do Sensoriamento Remoto e Geoprocessamento - O caso da Baía de Guanabara. 2003. 156f. Dissertação (Mestre em Geografia) - Instituto de Geociências, Universidade Federal do Rio de Janeiro, Rio de Janeiro, 2003.

TUCCI, C. E. M. Gerenciamento da drenagem urbana. Revista Brasileira de Recursos Hídricos, v.7, n.1, p.5-282, 2002.

VALLE JUNIOR, R. F.et al. Diagnóstico de mudanças e persistência de ocupação do solo entre 1978 e 2011 no IFTM-CAMPUS UBERABA, utilizando o "Land Change Modeler (LCM)”. Enciclopédia Biosfera, v.8, n.15, p.672-681, 2012.

VANZELA, L. S.et al. Influência do uso e ocupação do solo nos recursos hídricos do córrego Três Barras, Marinópolis. Revista Brasileira de Engenharia Agrícola e Ambiental, v.14, n.1, p.55-64, 2009.

VICENS, R. S. O transporte de sedimentos em suspensão como parte da análise ambiental da bacia hidrográfica do rio Mazomba. 1997. 117f. Dissertação (Mestre em Geografia) - Instituto de Geociências, Universidade Federal do Rio de Janeiro, Rio de Janeiro, 1997.

ZACCHI, R. C.; FARIA, M. M.; FERREIRA, E. S. Fatores morfométricos como condicionantes da ocorrência de enchentes na bacia do córrego Serafim, sub- bacia do rio Paraibuna, Juiz de Fora, MG. Boletim do Observatório Ambiental Alberto Ribeiro Lamego, v.6, n.1, p.151-160, 2012. 